\title{
Diş Çürüğü Deneyimi ile Ergenler ve Anneler arasındaki Tutarlılık Duygusu İlişkisinin Saptanmasi*
}

\author{
Ceren İLİSULU ${ }^{1}{ }^{1}$, Öykü HIZLIOĞLU ${ }^{2}{ }^{2}$, Mine KORUYUCU ${ }^{1}{ }^{1}$, Seçil ÖZKURT ${ }^{1}$, \\ Erkut BOLAT [ $^{3}$, Figen SEYMEN ${ }^{1}$
}

ÖZ

Amaç: Bu çalışmada diş çürüğü deneyimi ile ergen bireyler ve anneler arasındaki tutarlılık duygusu (SOC) ilişkisinin saptanması ve tutarll1ık duygusunun bireylerin oral hijyenleri üzerindeki etkisinin incelenmesi amaçlanmıştır.

Gereç ve Yöntemler: Bu çalışma 11-14 yaş grubu arasındaki sağlıklı 100 ergen birey ve anneleri dahil edilerek oral klinik muayeneleri DMFT indeksi ve Silness - Löe plak indeksi kullanılarak yapılmıştır. Demografik verilerden kardeş sayısı, anne eğitim durumu, baba eğitim durumu ve aile geliri değerlendirilmiştir. Tutarlılık duygusu, tutarlılık duygu skalasının 13 sorudan oluşan Türkçe'ye uyarlanmış kısa anket versiyonu kullanılarak uygulanmıştır. Yanıtlar, her soru için 7'li Likert ölçeği ile değerlendirilmiştir. Tutarlılık duygusu ile DMFT, plak indeksi, demografik veriler arasındaki ilişki istatistiksel olarak Spearman Korelasyon Analizi kullanılarak incelenmiştir.

Bulgular: Çocukların SOC değeriyle annelerin SOC değeri arasında orta düzeyde anlamlı ilişki bulunmuştur. Kardeş sayısı ve aile geliriyle çocukların SOC ve annelerin SOC değerleri arasında istatistiksel olarak anlamlı ilişki yoktur. Anne eğitim durumlarıyla çocukların SOC değeri arasında zayıf düzeyde anlamlı ilişki bulunurken, anne eğitim durumlarıyla annelerin SOC değeri arasında anlamlı ilişki bulunmamıştır. Çocukların DMFT değerleriyle çocukların SOC ve annelerin SOC değerleri arasında anlamlı bir ilişki bulunmazken çocukların DMFT değerleriyle çocuk plak indeksi arasında ise zayıf düzeyde anlamlı bir ilişki mevcuttur.

Sonuç: Sonuç olarak anneyle ergen bireylerin tutarlılık duyguları arasında ilişki gözlenirken, diş çürüğü ve tutarlılık duygusu arasında ilişki bulunamamıştır.

Anahtar Kelimeler: Psikososyal faktörler; stres; diş çürükleri; dental plak indeksi; demografik faktörler.

\section{Association between Dental Caries Experience and Sense of Coherence among Adolescents and Mothers}

\begin{abstract}
Aim: The aim of this study was to investigate relationship between caries experience and sense of coherence (SOC) among adolescent and their mothers and to investigate effects of SOC on oral hygiene of individuals and their experience of caries.

Material and Methods: In this study, 100 healthy adolescents aged 11-14 years and their mothers were evaluated and oral clinical examinations were performed using DMFT index and Silness - Lee plaque index. The number of siblings, parents' educational level, and family income were recorded as a demographic data. Sense of coherence was implemented using a short questionnaire version adapted to Turkish, consisting of 13 questions of the coherence emotion scale. The answers were evaluated with a 7-point Likert scale for each question. The correlation between SOC and DMFT, plaque index and demographic data were evaluated statistically using Spearman Correlation Analysis $(\mathrm{p}<0.05)$

Results: There was a significant relationship between SOC of children and SOC of mothers. No statistically significant relationship was found between the number of siblings and family income and SOC of children and mothers. While there was a weakly significant relationship between mother's educational level and SOC of children, no significant relationship was found between mother's educational status and SOC of mothers. There was no significant relationship
\end{abstract}

\footnotetext{
1 İstanbul Üniversitesi Diş Hekimliği Fakültesi Pedodonti Anabilim Dalı İstanbul, Türkiye,

2 Serbest Diş Hekimi, İstanbul, Türkiye

3 İstanbul Üniversitesi Tıp Fakültesi Biyoistatistik Anabilim Dalı İstanbul, Türkiye

*Bu çalışma, 4-7 Eylül 2019 tarihlerl arasında İstanbul'da düzenlenen 25. Uluslararası Diş Hekimliği kongresinde sözlü bildiri olarak sunulmuştur.
} 
between DMFT of children and SOC of mothers, but a weakly significant relationship was found between DMFT of children and children's plaque index.

Conclusion: As a result of this study; while there was a relationship between mothers and adolescents SOC, there was no correlation between caries experience and SOC.

Keywords: Psychosocial factors; stress; dental caries; dental plaque index; demographic factors.

\section{GIRIS}

Sağlık; biyolojik, çevresel, sosyal, kültürel ve ekonomik unsurlarla belirlenen çok boyutlu bir kavramdır (1). Diş çürüğü, ağız sağlığının yanı sıra genel sağlığı da olumsuz yönde etkileyebilen önemli bir halk sağlı̆̆ı sorunudur. Dünyada en sık görülen kronik hastalık olarak da tanımlanabilen diş çürüğü, kalsifiye dokuların yıkımı ve lokalize çözünmesiyle sonuçlanan dişlerin mikrobiyolojik enfeksiyöz bir hastalığıdır (2). Çürük deneyimi, ağrının yanı sira ergen bireylerin ve ebeveynlerinin hayat kalitesini de olumsuz etkileyebilmektedir (3). Ayrıca diş çürüğü, bazı psikososyal değişkenlerle ilgili de olabilmektedir. $\mathrm{Bu}$ değişkenlere tutarlılık hissi örnek verilebilir (4).

Tutarlılık duygusu (Sense of Coherence - SOC), Aaron Antonovsky tarafindan 1980'li yılların başında geliştirilen bir kavram olup, meydana getirdiği bu modele Salutogenesis adını vermiştir. 'Salut' kelimesi köken olarak iyi olmak, sağlıklı olmak olarak tanımlanmaktadır. Bu kavram daha çok hastalığın kaynağını araştıran, bireyi sağlıklı veya sağlıksız olarak adlandırmaktan ziyade sağlıklılık veya sağlıksızlık durumunu derecelendirme yaparak değerlendiren bir modeldir (5). Tutarlılık duygusu; anlaşılabilirlik, yönetilebilirlik ve anlamlılık olmak üzere üç kavramdan oluşmaktadır $(6,7)$. Bu kavramlar bireylerin stresli koşullara maruz kalmalarından sonra bazılarının bunu tolere edebilmelerine rağmen bazılarının neden tolere edemediklerini açıklamaktadır (8). SOC, bireylerin hayatlarında karşılaştıkları çeşitli streslerle, gerginlik ve güçlüklerle nasıl başa çıkabildikleriyle ilgilidir $(9,10)$. Bu kavramın gelişimi çocukluk döneminde başlamakta ergenlik boyunca ana duygu oluşmakta ergenlik dönemi sonrasında ise çok küçük değişiklikler olabilmektedir (11). Etkili sağlık davranışlarının benimsenmesi ve kabul oranının artması için SOC kavramının da kuvvetli olması gerekmektedir (12). SOC kavramının ölçülmesi Antonovsky tarafından geliştirilmiş olan uyum anlayış ölçeği kullanılarak yapılır ve cevaplar Likert ölçeği kullanılarak verilmelidir $(13,14)$.

Son yirmi yılda yapılan çalışmalar sonucunda SOC ile kayg1, fiziksel aktivite, diyet faaliyetleri ve algilanan sağlık arasında güçlü bir korelasyon olduğu sonucuna varılmıştır (15). Bu bulgular SOC ve ağız sağlığı durumu için de geçerlidir $(16,17)$. Birçok araştırmacı SOC ve ağız sağlığı arasında anlamlı ilişkiler olduğunu bildirmiştir $(18,19)$. Antonovsky'nin salutogenik teorisi, ağız sağlığına da uygulanmıştır. SOC'nin sağlık davranışı ile ilişkisi daha önce ergenler arasında tam olarak incelenmemiştir. Yapılan bir çalışmada zayıf SOC'a sahip ergenlerin, ağız sağlı̆̆1 problemlerine sahip olma, diş hekimi ile temas kurmama olasılığının yüksek olduğu bildirilmiştir (16). Yapılan bazı çalışmalar, okul öncesi çocukların annelerinin daha düşük SOC'sinin, daha fazla sayıda çürük, dolgulu ve çürük diş ile ilişkili olduğunu göstermiştir (4).

Bireylerin ağız sağlıklarına ilişkin bilgilerin değerlendirilmesinde Dünya Sağlık Örgütünün sistemlerinin kullanılması önerilmektedir. $\mathrm{Bu}$ anlamda toplumdaki diş çürüğü oranlarının ve karşılaştırmalarının yapılabilmesi için DMFT, DMFS gibi indekslerin kullanımı önemlidir (20).

$\mathrm{Bu}$ çalışmada, diş çürüğü deneyimi ile ergen bireyler ve anneler arasındaki tutarlılık duygusu ilişkisinin saptanması ve tutarlılık duygusunun bireylerin oral alışkanlıkları, çürük deneyimleri üzerindeki etkisinin incelenmesi amaçlanmıştır. Araştırma sonunda, ergen bireyler ve anneler arasındaki tutarlilık duygusunun sağlıklı 11-14 yaş grubundaki bireylerin diş çürüğü deneyimi ile olan iliş̧kisi saptanarak, tutarlılık duygusu seviyesinin oral hijyen alışkanlıkları, çürük deneyimi üzerindeki etkisi ile ilgili ileride yapılacak çalışmalarda kolaylık sağlayacağı düşünülmektedir.

\section{GEREÇ VE YÖNTEMLER \\ Örneklem}

Bu araştırma 15 Şubat 2019 ile 15 Nisan 2019 tarih aralığında İstanbul Üniversitesi Diş Hekimliği Fakültesi Pedodonti Anabilim Dalı'na başvurmuş sağlıklı 11-14 yaş grubu arasındaki 100 ergen bireyler ve anneleri ile gerçekleştirilmiştir. Çalışmanın yapıldığı tarih aralığında çalışmaya katılmak istemeyen, tam olarak doldurulmayan ve yarım bırakılan anketler çalışma dışı bırakılmıştır. Alfa hata 0,$05 ; \% 90$ güçte R1=0,6 korelasyon katsayısını 0,3 etki büyüklüğü ile tespit etmek için en az 74 örneklem sayısına ulaşılması hedeflenmiştir.

\section{Veri Toplama Araçları}

Bireylerden ve ailelerden gönüllü onam formu alındıktan sonra, araştırmaya katılmayı kabul eden ergen bireyler ve annelerinin tutarlılık duygusu, tutarlılık duygu skalasının 13 sorudan oluşan Türkçe'ye uyarlanmış kısa anket versiyonu uygulanarak değerlendirildi. Cevaplar ise 7 noktalı Likert ölçeği kullanılarak verildi.

Uyum Anlayışı Ölçeği: Antonovsky (10) tarafından SOC kavramının ölçülebilmesi amacıyla geliştirilmiştir. $\mathrm{Bu}$ ölçek, bireylerin maruz kaldığı olumsuz durumlara ve çevrelerine karşı uyum derecelerinin belirlenmesini sağlar (12). Ölçeğin Türkçeye uyarlaması Scherler ve Lajunen (1997) tarafından yapılmıştır (5). Tutarlılık duygusunu ölçmenin en yaygın yolu 29 maddelik OLQ-29'dur. Kısaltılmış 13 maddelik tutarlılık duygusu ölçeği; dört anlamlılık, beş anlaşılabilirlik ve dört yönetilebilirlik öğesi içerir. Antonovsky, bu üç tutarlılık duygusu bileşeninin kendine uygun yapılar olarak ölçülmemesi gerektiğini vurgulamıştır, çünkü ölçek, birbiriyle ilişkili üç bileşenden oluşan küresel bir yönelim, tutarlılık duygusu ölçmek için geliştirilmiştir. $\mathrm{Bu}$, çeşitli çalışmalarda üç bileşen arasındaki yüksek karşılıklı ilişkilerin bulunmasından kaynaklanmaktadır (13). Cevaplar, her soru için aşırı cevapların (1 ve 7) formüle edildiği 7 noktalı Likert ölçeği kullanılarak verilmelidir (14).

İlgili yaş aralığında bulunmayan, sistemik hastalığı bulunan çocuklar ve 13 sorunun tamamını yanıtlamayan katılımcılar çalışmadan hariç tutuldu. Ergen bireylerin ve annelerinin oral klinik muayenesi DMFT indeksi ve Silness ve Löe plak indeksi kullanarak yapıldı. 


\section{Araştırmanın Etik Boyutu}

$\mathrm{Bu}$ araştırma İstanbul Üniversitesi Diş Hekimliği Fakültesi Pedodonti Anabilim Dalı'nda gerçekleştirilmiş olup İstanbul Üniversitesi Diş Hekimliği Fakültesi Etik Kurul'undan onay alınmıştır (22.01.2018/292253). Araştırma kapsamında bulunan ergen bireyler ve annelerine, veriler toplanmaya başlamadan önce araştırmanın amacı, nasıl uygulanacağı, uygulanan ölçek ve yapılacak olan oral klinik muayene hakkında bilgiler verildi. Bireylerin çalışmaya katılmayı kabul etmeleri durumunda, istedikleri zaman araştırmadan çekilebilme haklarının olduğu, elde edilen bilgilerin gizli tutulacağ ve gönüllülük hakları ile ilgili bilgiler verilerek bilgilendirilmiş gönüllü onam formu ile yazılı olarak onamları alınmıştır. Bu çalışma araştırma ve yayın etiği kurallarına uyularak hazırlanmıştır.

\section{İstatistiksel Analiz}

Verilerin analizi SPSS 23.0 paket programı ile yapıldı. Hastaların niteliksel özellikleri tablolarda sayı (n) ile gösterildi. Yaş ve cinsiyet açısından homojenlik için KiKare testi kullanıldı. Sayısal değişkenlerin normal dağılıma uygunluğu Kolmogorov-Smirnov testi ile değerlendirildi. Normal dağılım göstermeyen değişkenler arasındaki korelasyon "Spearman Korelasyon Analizi” ile incelendi. Anlamlılık $\mathrm{p}<0,05$ ve $\mathrm{p}<0,01$ olarak değerlendirildi.

\section{BULGULAR}

Çalışmaya 11-14 yaş arası 53 erkek, 47 kız ergen birey ve anneleri katılmıştır. Yapılan anket doğrultusunda anne ve çocukların tutarlılık duyguları ölçülmüş ve bu değerler "Ergen SOC” ve “Anne SOC” olarak tablolara yazılmıştır. Çalışmaya ait demografik veriler Tablo 1'de görülmektedir. Cinsiyetin homojenlik testinde $\mathrm{p}=0,617$ olup erkek ve kadın dağılımı homojendir. Yaşın homojenlik testinde $\mathrm{p}=0,017$ olup yaş dağılımı homojen değildir. 11 yaş grubu oranı yüksektir.

Tablo 1. Çalışmaya katılan ergen bireylerin ve ebeveynlerinin genel bilgileri

\begin{tabular}{|c|c|c|}
\hline & & $\%$ \\
\hline \multirow[t]{2}{*}{ Cinsiyet } & Erkek & 53 \\
\hline & Kadın & 47 \\
\hline \multirow[t]{4}{*}{ Yaş } & 11 & 37 \\
\hline & 12 & 27 \\
\hline & 13 & 16 \\
\hline & 14 & 20 \\
\hline \multirow{5}{*}{$\begin{array}{l}\text { Anne Eğitim } \\
\text { Durumu }\end{array}$} & Okuryazar değil & 5 \\
\hline & İlkokul & 48 \\
\hline & Ortaokul & 10 \\
\hline & Lise & 28 \\
\hline & Üniversite & 9 \\
\hline \multirow{5}{*}{$\begin{array}{l}\text { Baba Eğitim } \\
\text { Durumu }\end{array}$} & Okuryazar değil & 2 \\
\hline & İlkokul & 39 \\
\hline & Ortaokul & 13 \\
\hline & Lise & 35 \\
\hline & Üniversite & 11 \\
\hline \multirow[t]{3}{*}{ Aile Geliri } & Asgari Ücret altı & 14 \\
\hline & Asgari ücret & 21 \\
\hline & Asgari ücret üstü & 65 \\
\hline
\end{tabular}

Ergen bireylerin SOC değerleri ile anne SOC değerleri arasında pozitif yönde orta düzeyde anlamlı ilişki bulunurken $(\mathrm{r}=0,603 ; \mathrm{p}<0,001)$; kardeş sayısı ve aile geliri ile ergen SOC ve anne SOC değerleri arasında anlamlı ilişki bulunmamıştır ( $\mathrm{p}>0,05)$ (Tablo 2).

Tablo 2. Ergen SOC; Anne SOC ile Kardeş sayısı, Aile geliri, Anne ve Baba eğitim durumu karşılaştırmaları

\begin{tabular}{|l|c|c|c|}
\hline \multicolumn{2}{|c|}{} & Ergen SOC & Anne SOC \\
\hline Anne SOC & $\mathrm{r}$ & $\mathbf{0 , 6 0 3}$ & 1,000 \\
\cline { 2 - 4 } & $\mathrm{p}$ & $\mathrm{p}<0,001$ & \\
\hline Kardeş Sayısı & $\mathrm{r}$ & 0,068 & 0,120 \\
\hline Aile Geliri & $\mathrm{r}$ & 0,163 & 0,234 \\
\hline & $\mathrm{p}$ & 0,106 & 0,077 \\
\hline $\begin{array}{l}\text { Anne Eğitim } \\
\text { durumu }\end{array}$ & $\mathrm{r}$ & $0,299^{* *}$ & 0,449 \\
\hline & $\mathrm{p}$ & 0,003 & 0,621 \\
\hline $\begin{array}{l}\text { Baba Eğitim } \\
\text { durumu }\end{array}$ & $\mathrm{r}$ & 0,022 & 0,001 \\
\hline & $\mathrm{p}$ & 0,826 & 0,989 \\
\hline
\end{tabular}

Anne eğitim durumu ile ergen SOC değerleri arasında zayıf düzeyde anlamlı ilişki bulunmuştur ( $r=0,299$; $\mathrm{p}<0,001)$. Anne eğitimi ile anne SOC değerleri arasında anlamlı bir ilişki yoktur $(\mathrm{r}=0,050 ; \mathrm{p}>0,05)$. Baba eğitim durumu ile ergen SOC ve anne SOC değerleri arasında anlamlı bir ilişki bulunmamıştır ( $\mathrm{p}>0,05)$ (Tablo 2).

Tablo 3. Anne DMFT, Ergen DMFT ile Ergen SOC, Anne SOC, Anne plak ve Ergen plak indeksi arasındaki ilişsi

\begin{tabular}{|l|c|c|c|c|c|}
\hline \multicolumn{2}{|c|}{} & $\begin{array}{c}\text { Ergen } \\
\text { SOC }\end{array}$ & $\begin{array}{c}\text { Anne } \\
\text { SOC }\end{array}$ & $\begin{array}{c}\text { Anne Plak } \\
\text { İndeksi }\end{array}$ & $\begin{array}{c}\text { Ergen } \\
\text { Plak } \\
\text { İndeksi }\end{array}$ \\
\hline $\begin{array}{l}\text { Anne } \\
\text { DMFT }\end{array}$ & $\mathrm{r}$ & 0,006 & 0,025 & 0,030 & - \\
\cline { 2 - 6 } & $\mathrm{p}$ & 0,954 & 0,801 & 0,764 & - \\
\hline $\begin{array}{l}\text { Ergen } \\
\text { DMFT }\end{array}$ & $\mathrm{r}$ & 0,006 & 0,178 & - & $\mathbf{0 , 2 7 2 *}$ \\
\cline { 2 - 6 } & $\mathrm{p}$ & 0,950 & 0,077 & - & 0,006 \\
\hline
\end{tabular}

Anne DMFT değeri ile ergen SOC, anne SOC ve anne plak indeksi arasında anlamlı bir ilişki bulunmamıştır ( $>0$,05) (Tablo 3). Ergen DMFT değeri ile ergen bireyin plak indeksi arasında pozitif yönde zayıf düzeyde anlamlı bir ilişki vardır $(r=0,272 ; p<0,001)$. Ergen bireyin DMFT değeri ile ergen SOC ve anne SOC değerleri arasında anlamlı bir ilişki bulunmamıştır ( $\mathrm{p}>0,05)$ (Tablo 3). 


\section{TARTIŞMA VE SONUÇ}

Diş çürüğü, çocukların büyük bir bölümünü etkileyen evrensel çapta en önemli enfeksiyöz çocukluk hastalıklarından birisidir. Antonovsky'nin öne sürdüğü salutojenik sağlık modeli içinde, SOC terimi önemli bir yere sahiptir. SOC'nin kökenleri hakkında az bilgi bulunsa da SOC ile toplumdaki refah düzeyi arasında kuvvetli bir ilişki bulunduğuna dair kanıtlar mevcuttur (21).

SOC, psikososyal bir belirleyici olup insanların sağlıkla ilgili davranışlarını etkileyebilmektedir. Yapılan araştırmalarda yüksek SOC sahibi insanların düşük SOC sahibi olanlara oranla yaşamlarında daha sağlıklı olduğu belirtilmiștir (22). Yüksek SOC sahibi bireylerin daha sağlıklı bir yaşam tarzına sahip olmalarında sosyal sınıf ve eğitim durumunun etkili olmadığı bildirilmiştir. Yüksek SOC sahibi olan yetişkin bireylerde düzenli beslenme, fiziksel aktiviteler, alkol ve sigaranın minimum düzeyde kullanıldığı gözlemlenmiştir (23).

Yapılan araştırmalar sonucunda çocuk ve ergenlerin ağız sağlığı ve davranışlarında annelerin önemli bir etkisi olduğu belirtilmektedir. Bu durumda çocukların sağlık sorunlarının sorumluluğunun ebeveynlerde olmasının yanı sıra annelerin psikososyal faktörlerinin çocuğun ağız sağlığı durumunu da etkilediği düşünülmektedir (24). Bu nedenle, ilgili semptomların, hastalıkların ve tedavilerin çocuklarının yaşam kalitesini nasıl etkileyebileceği de dahil olmak üzere annelerin çocuklarının ağız sağlığı sorunlarına yönelik algılarını değerlendirmek büyük önem taşımaktadır (21).

Tutarlılık duygusu ve ağız sağlığı arasındaki ilişkiyi değerlendiren çok az sayıda çalışma bulunmaktadır. Savolainen ve ark. (21) yaptıkları çalışmada, tutarlılık duygusunun ağı sağllğ $\breve{g}_{1}$ ile ilgili yaşam kalitesi konusundaki belirleyiciliğini değerlendirmişler ve yüksek SOC'ye sahip kişilerin zayıf SOC'ye sahip olanlara göre önemli ölçüde daha az oral problemi olduğunu bildirmişlerdir. Lage ve ark.'nın (25) yaptıkları bir çalışmada ise yüksek diş çürüğüne sahip olan ergen bireylerin annelerinin düşük SOC değerine sahip olduklarını çünkü sağlık ile ilgili bilgilerin iletilmesinde ve çocukların sağlıklarının korunmasında genellikle annelerin sorumlu olduklarını bildirmişlerdir. Freire ve ark. (17) yaptıkları çalışmada, anneleri yüksek SOC skoruna sahip ergen bireylerin diş hekimini daha az ziyaret ettiklerini bildirmişlerdir. Savolainen ve ark. (26) yaptıkları çalışmada ise çocukların ve bakıcılarının oral sağlık hijyenleri ile tutarlılık duyguları arasındaki ilişkiyi incelemiş ve aralarında anlamlı bir ilişki bulunamamıştır. Bizim çalışmamızda diş çürüğü deneyimi ile tutarlılık duygusu arasında anne ve ergen bireyde anlamlı bir korelasyon bulunamamıştır. Khatri ve ark. (27) 3-5 yaş arasındaki anaokuluna giden çocukların dmft değerleri ile annelerinin tutarlılık duyguları arasındaki ilişkiyi değerlendirmiş ve annenin tutarlılık duygusu değerindeki artışı, çocukların dmft değerindeki azalma ile ilişkilendirmişlerdir. Bizim çalışmamızda ise ergen bireyin DMFT değeri ile annenin tutarlılık duygusu arasında anlamlı bir ilişki bulunamamıştır.

$\mathrm{Bu}$ çalışmada sosyoekonomik durumu düşük ailelerin ergen bireylerinin sosyoekonomik durumu yüksek ailelere göre daha fazla diş çürüğü tecrübesine sahip olduğu tespit edilmiştir. Halberg ve ark. (28) yaptıkları çalışmada düşük gelirli ebeveynlerin günlük yaşam aktivitelerini yönetme konusundaki zorluklarının, sistemin yeterli olduğu ve diş sağlığ hizmetlerinin ücretsiz olduğu durumlarda bile çocukların diş hekimi randevularına katılmamasının ana nedeni olduğunu göstermiştir. Ailenin sosyoekonomik durumunun ergen birey ve anne için strese neden olabilecek bir faktör olduğu göz önüne alındığında, bunun aynı zamanda düşük SOC değerleri ile de ilişkili olabileceği öne sürülmektedir. $\mathrm{Bu}$ nedenle, SOC ve sosyoekonomik özellikler birbiriyle ilişkilidir ve diş çürüğü görülme sıklığı ile ilişkili olabilir (10). De Silva ve ark. (29) yaptıkları çalışmada sosyoekonomik durumu düşük yüksek SOC seviyesine sahip annelerin, düşük SOC seviyeli annelere kıyasla çocuklarını daha sıklıkla diş hekimine götürdüklerini bildirmişlerdi. SOC, insanın çevresinin daha az stresli, daha az rahatsız edici olduğu algısını belirlediğinden, annelerin çocuklarını diş hekimi ziyaretine götürmek gibi etkili davranış seçimlerinin kolaylaştırmasını sağlayabilir (10). Bizim çalışmamızda ise sosyoekonomik durum ile tutarlılık duygusu arasında anlamlı bir ilişki bulunamamıștır.

Tutarlılık duygusu stresle başa çıkabilme, yaşam yönetimi ve karşılaşılan sorunları çözebilme ile ilgilidir. Bireylerin olduğu gibi ailelerin de tutarlılık duyguları olabilir (30). Bu sebeple anne ve çocukların tutarlılık duyguları arasında bir ilişki olması gerektiği düşünülebilir. Bizim çalışmamızda da anne ile çocuk tutarlılık duyguları arasında anlamlı bir ilişki saptanmıştır.

$\mathrm{Bu}$ çalışmanın sonucunda; anne ve ergen bireyler arasındaki tutarlılık duyguları arasında bir ilişki gözlenirken, diş çürüğü ve tutarlılık duygusu arasında bir ilişki bulunmamıştır. Bunun sebebi çalışmanın belirli bir yaş grubunda belirli sayıda kişiler üzerinde gerçekleştirilmesi olabilir. Bu konu ile ilgili daha geniş yaş grubunda ve daha çok kişi üzerinde yapılacak çalışmalara gereksinim duyulmaktadır.

Yazarların Katkıları: Fikir/Kavram: F.S.; Tasarım: C.İ,, Ö.H., F.S.; Veri Toplama ve/veya İșleme: C.İ.; Ö.H., S.Ö.; Analiz ve/veya Yorum: C.İ., Ö.H., M.K., E.B.; Literatür Taraması: C.İ., Ö.H., S.Ö.; Makale Yazımı: C.İ., Ö.H.; Eleştirel İnceleme: M.K., F.S.

\section{KAYNAKLAR}

1. Park K. Park's Textbook of Preventive and Social Medicine. 23rd ed. India: Bhanot Publication; 2014.

2. Roberson TM, Heymann HO, Swift EJ. Art and Science of Operative Dentistry. 6th ed. Orlando: Mosby Inc; 2006.

3. Freire M, Hardy R, Sheiham A. Mothers' sense of coherence and their adolescent children's oral health status and behaviours. Community Dent Health. 2002; 19(1): 24-31.

4. Bonanato K, Paiva SM, Pordeus IA, Ramos-Jorge ML, Barbabela D, Allison PJ. Relationship between mothers' sense of coherence and oral health status of preschool children. Caries Res. 2009; 43(2): 1039.

5. Çeçen AR. Üniversite öğrencilerinde yaşam doyumunu yormada bireysel bütünlük (tutarlılık) 
duygusu, aile bütünlük duygusu ve benlik saygısı. Eğitimde Kuram ve Uygulama. 2008; 4(1): 19-30.

6. Antonovsky A. The salutogenic model as a theory to guide health promotion. Health Promot Int. 1996; 11(1): 11-8.

7. Eriksson M, Lindström B. Antonovsky's sense of coherence scale and the relation with health: A systematic review. J Epidemiol Community Health. 2006; 60(5): 376-81.

8. Viswanath D, Krishna AV. Correlation between dental anxiety, sense of coherence (SOC) and dental caries in school children from Bangalore North: a cross-sectional study. J Indian Soc Pedod Prev Dent. 2015; 33(1): 15-8.

9. Antonovsky A. The structure and properties of the sense of coherence scale. Soc Sci Med. 1993; 36(6): 725-33.

10. Antonovsky A. Unraveling the mystery of health. How people manage stress and stay well. 1st ed. San Francisco: Jassey-Bass; 1987.

11. Çeçen AR. Aile bütünlük (tutarlılık) duygusu ölçeği (ABDÖ-K) kısa formunun Türkçe'ye uyarlanması: geçerlik ve güvenirlik çalışmaları. Kuram ve Uygulamada Eğitim Bilimleri. 2007; 7(3): 1199220.

12. Marsh P, Martin MV. Oral microbiology. 4th ed. Oxford: Wright; 1999.

13. Caufield PW, Griffen AL. Dental caries. An infectious and transmissible disease. Pediatr Clin North Am. 2000; 47(5): 1001-9.

14. Tennant M, Namjoshi D, Silva D, Codde J. Oral health and hospitalization in western Australian children. Aust Dent J. 2000; 45(3): 204-7.

15. National Institute of Dental and Craniofacial Research. Oral health in America: a report of the surgeon general. Rockville: U.S. Public Health Service; 2000.

16. Featherstone JD, Adair SM, Anderson MH. Caries management by risk assessment: consensus statement. J Calif Dent Assoc. 2003; 31(3): 257-69.

17. Freire M, Hardy R, Sheiham A. Mothers' sense of coherence and their adolescent children's oral health status and behaviours. Community Dent Health. 2002; 19(1): 24-31.

18. Lindmark U, Hakeberg M, Hugoson A. Sense of coherence and its relationship with oral healthrelated behaviour and knowledge of and attitudes towards oral health. Community Dent Oral Epidemiol. 2011; 39(6): 542-53.

19. Bernabe E, Watt RG, Sheiham A, SuominenTaipale AL, Uutela A, Vehkalahti MM. Sense of coherence and oral health in dentate adults: findings from the Finnish health 2000 survey. J Clin Periodontol. 2010; 37(11): 981-7.

20. Kuter B. İzmir ilindeki 6 yaş grubu çocukların ağızdiş sağlığı durumlarının değerlendirilmesi ve önemli çürük indeksinin önemi. Atatürk Üniv. Diş Hek. Fak. Derg. 2019; 29(2): 176-81.

21. Savolainen J, Suominen-Taipale A, Uutela A, Martelin T, Niskanen M, Knuuttila M. Sense of coherence as a determinant of toothbrushing frequency and level of oral hygiene. J Periodontol. 2005; 76(6): 1006-12.
22. Sheiham A. Changing trends in dental caries. Int $\mathrm{J}$ Epidemiol. 1984; 13(2): 142-7.

23. Griffin SO, Griffin PM, Swann JL, Zlobin N. Estimating rates of new root caries in older adults. J Dent Res. 2004; 83(8): 634-8.

24. De Grauwe A, Aps JK, Martens LC. Early childhood caries (ECC): what's in a name. Eur J Paediatr Dent. 2004; 5(2): 62-70.

25. Lage CF, Fulgencio LB, Correa-Faria P, SerraNegra JM, Pordeus IA. Association between dental caries experience and sense of coherence among adolescents and mothers. International Journal of Paediatric Dentistry. 2017; 27(5): 412-9.

26. Savolainen J, Suominen-Taipale A, Uutela A. Sense of coherence associates with oral and general health behaviors. Community Dent Health. 2009; 26(4): 197-203.

27. Khatri SG, Acharya S, Srinivasan SR. Mother's sense of coherence and oral health related quality of life of preschool children in Udupi Taluk. Community Dent Health. 2014; 31(1): 32-6.

28. Hallberg U, Camling E, Zickert I, Robertson A, Berggren U. Dental appointment no-shows: Why do some parents fail to take their children to the dentist. Int J Paediatr Dent. 2008; 18(1): 27-34.

29. Da Silva AN, Mendonca MH, Vettore MV. The association between low socioeconomic status mother's sense of coherence and their child's utilization of dental care. Community Dent Oral Epidemiol. 2011; 39(2): 115-26.

30. Antonovsky A, Talma S. Family sense of coherence and family adaptation. Journal of Marriage and Family. 1988; 50(1): 79-92. 